\title{
PENERAPAN PEMBELAJARAN PHONICS MELALUI RABS (RHYMING, ALLITERATION, BLENDING, SEGMENTATION) UNTUK MELATIH KETRAMPILAN PELAFALAN KATA BAHASA INGGRIS SISWA
}

\author{
${ }^{1 *}$ S. Agus Santoso, ${ }^{2}$ Raden Agus Budiharto, ${ }^{3}$ Ratna Ani Lestari \\ ${ }^{1}$ Universitas Sebelas Maret, Solo, Jawa Tengah, Indonesia \\ ${ }^{2}$ Universitas Madura, Pamekasan, Jawa Timur, Indonesia \\ ${ }^{3}$ Universitas Wijaya Kusuma, Surabaya, Jawa Timur, Indonesia \\ E-mail : "budiharto@unira.ac.id
}

Manuskrip: September -2021; Ditinjau: September -2021; Diterima: Oktober -2021;

Online: Januari-2022; Diterbitkan: Januari-2022

\begin{abstract}
ABSTRAK
Terampil melafalkan kata bahasa Inggris dengan baik merupakan suatu ketrampilan yang dianggap paling sulit untuk didapatkan bagi pelajar siswa SMP Qurrotul Uyun Pamekasan yang sering menggunakan bahasa Madura sebagai bahasa sehari-harinya. Apalagi mereka sangat jarang memiliki kesempatan untuk mempraktekkan pelafalan kata atau kalimat bahasa Inggris di dalam kelas maupun di luar kelas. Mengingat ketrampilan melafalkan kata-kata bahasa Inggris dengan benar dan akurat sangat diperlukan bagi siswa yang sedang belajar bahasa Ingris karena dapat berpengaruh terhadap keberhasilan mereka dalam membaca (reading) dan berbicara (speaking) maka tim abdimas berinisiatif menerapkan pembelajaran phonics, yaitu proses yang menghubungkan bentuk suara yang didengarkan dengan bentuk suara yang ditulis. Kegiatan yang dilakukan dalam pengabdian masyarakat ini berbentuk pelatihan dan pendampingan dengan menggunakan RABS (Rhyming, Alliteration, Blending, Segmentation) yang melibatkan siswa kelas 7 SMP Qurrotul Uyun Pamekasan sebagai sasaran utamanya. Mempresentasikan materi, menjelaskan RABS, memberikan pelatihan, melakukan pendampingan dan melakukan evaluasi merupakan tahapan-tahapan metode yang digunakan dalam pengabdian ini. Pelaksanaan kegiatan ini berlangsung selama tiga hari yaitu dari tanggal 25, 26 sampai tanggal 27 Januari 2021 di kelas SMP Qurrotul Uyun Pamekasan. Hasil dari kegiatan pengabdian ini menunjukkan bahwa pembelajaran phonics yang diterapkan melalui tahapan rhyming, alliteration, blending dan segmentation pada siswa kelas 7 SMP Qurrotul Uyun Pamekasan yang sehariharinya menggunakan bahasa Madura sebagai bahasa Ibu mereka tidak hanya dapat membantu menambah pengetahuan English phonology mereka tetapi juga dapat membantu meningkatkan ketrampilam mereka dalam melafalkan huruf-huruf bahasa Inggris dan kata-kata bahasa Inggris.
\end{abstract}

Kata Kunci: Pelafalan, Pembelajaran Phonics, Identifikasi Suara 


\section{PENDAHULUAN}

Memiliki ketrampilan melafalkan kata bahasa Inggris dengan jelas dan tepat merupakan hal yang sangat perlu dimiliki oleh pelajar jika mereka ingin berkomunikasi dengan lancar dan benar ketika menggunakan bahasa tersebut. Akan tetapi banyak pelajar yang bahasa sehari-harinya bukan bahasa Inggris mengalami kesulitan dan masih berusaha untuk belajar melafalkan kata-kata bahasa Inggris dengan tepat dan benar. Menurut Gilakjani (2016) terampil melafalkan kata bahasa Inggris merupakan suatu ketrampilan yang dianggap paling sulit untuk didapatkan bagi pelajar karena mereka harus meluangkan banyak waktu untuk meningkatkan ketrampilan tersebut. Sementara Albiladi (2019) meyakini bahwa bahasa pertama atau bahasa ibu seseorang dapat berpotensi memiliki dampak yang kurang bagus terhadap kemampuannya dalam mendengar dan menghasilkan kata-kata bahasa Inggris ketika seseorang tersebut melafalkannya. Kedua pernyataan tadi dapat menandakan bahwa pelajar yang bahasa ibunya bukan bahasa Inggris dapat berpotensi membuat kesalahan dalam pelafalan. Kesalahan pelafalan yang dilakukan oleh pelajar bahasa Inggris dapat dianggap bermasalah karena sekalipun mereka menggunakan tata bahasa yang benar dan kosakata tingkat lanjutan, pendengar bisa saja mengalami kesulitan untuk memahaminya. Oleh sebab itu, guru bahasa Inggris seharusnya sudah terlatih dengan baik dalam pelafalan agar bisa meningkatkan ketrampilan pelajar dalam melafalkan bahasa Inggris (Shahzada et al., 2012). Namun kenyataannya banyak guru yang tidak menyadari akan pentingnya pelafalan. Mereka enggan mengajarkan pelafalan bahasa Inggris di kelas, karena tidak adanya petunjuk dan aturan yang jelas di buku pelajaran (Griffiths, 2011) sehingga mereka hanya mengajarkan tata bahasa (grammar), kosakata (vocabulary), dan empat keterampilan bahasa (listening, writing, reading, speaking) untuk pelajar mereka tanpa memasukkan pelafalan bahasa Inggris ke dalam kurikulum (Hismanoglu \& Hismanoglu, 2011). Serta para guru juga berpikir bahwa mengajarkan pelafalan bahasa Inggris terlalu sulit dan monoton bagi pelajar (Harmer, 2001).

Tujuan pembelajaran pelafalan pada dasarnya tidak menginstruksikan pelajar untuk melafalkan kata bahasa asing atau bahasa Inggris seperti penutur aslinya. Karena menurut (James, 2010) pelafalan yang tepat yang dapat dipahami didasarkan pada tiga tingkatan. Pada tingkatan 1, apa yang dituturkan oleh si penutur tidak dapat dipahami oleh orang lain. Si penutur menggunakan suara yang salah ketika menghasilkan kata-kata bahasa Inggris. Pada tingkatan 2, apa yang dituturkan oleh si penutur dapat dipahami oleh orang lain tetapi pelafalan penutur tidak dapat dipahami untuk didengarkan karena si penutur memiliki logat yang aneh. Pada tingkatan 3, apa yang dituturkan oleh si penutur dapat dipahami oleh orang lain dan bahasa Inggris si penutur dapat dipahami untuk didengarkan. Sementara pelafalan bahasa Inggris siswa kelas 7 SMP Qurrotul Uyun PamekasanMadura berada pada tingkatan 1, yaitu sering menghasilkan suara yang salah ketika melafalkan kata-kata bahasa Inggris. Temuan ini diperoleh oleh tim abdimas setelah melakukan beberapa kali observasi ke kelas (yaitu pada tanggal 7, 14, 21 Januari 2021) saat proses belajar mengajar bahasa Inggris sedang berlangsung. Adapun 
beberapa penyebabnya adalah karena siswa tidak memiliki kelas khusus untuk berlatih pelafalan bahasa Inggris secara intensif. Dalam satu minggu mereka hanya mendapatkan pelajaran bahasa Inggris satu kali pertemuan saja, dengan durasi waktu 3 jam. Buku pelajaran yang digunakan berjudul "When English Rings a Bell" yang hanya memfokuskan pada ketrampilan membaca, mendengarkan dan penguasaan kosakata. Mereka juga memiliki kesempatan yang sangat minim untuk mempraktekkan pelafalan kata atau kalimat bahasa Inggris dengan baik di dalam kelas ataupun di luar kelas sehingga hal ini berakibat pada kemampuan mendengar (listening skill) dan berbicara (speaking skill) mereka sangat tidak bagus. Di samping itu, siswa cenderung menggunakan intonasi, proses fonologi dan aturan pelafalan dari Bahasa Madura ke Bahasa Inggris.

Adanya temuan-temuan permasalahan pelafalan bahasa Inggris yang dialami oleh siswa dan mengingat ketrampilan melafalkan kata-kata bahasa Inggris dengan benar dan akurat sangat diperlukan bagi siswa yang sedang belajar bahasa Inggris karena dapat berpengaruh terhadap keberhasilan dalam membaca (reading) dan berbicara (speaking) maka tim abdimas berinisiatif menerapkan pembelajaran phonics sebagai cara yang tepat untuk memberikan pengetahuan dan ketrampilan pada siswa SMP Qurrotul Uyun Pamekasan tentang bagaimana melafalkan katakata bahasa Inggris dengan tepat dan benar. Phonics mempelajari tentang hubungan antara huruf dengan suara dan dapat dijadikan sebagai cara untuk mengajar siswa tentang bagaimana mengucapkan kata-kata berdasarkan ejaan (Grado, 2014). Berkenaan dengan pernyataan tadi, siswa juga diharapkan dapat mengetahui aturan perubahan-perubahan suara di suatu huruf kata bahasa Inggris agar tidak terjadi kesalahan saat melafalkan. Sebagai contoh, melafalkan perbedaan suara di huruf "c" pada kata nice dan cat. Huruf "c" berubah menjadi suara /s/ ketika melafalkan kata nice /nars/ sedangkan huruf "c" berubah menjadi suara /k/ ketika melafalkan kata cat $/ \mathrm{kæt} /$. Perubahan suara di huruf "c" menjadi suara $/ \mathrm{k} /$ terjadi apabila huruf "c" bertemu dengan huruf vokal "o", "a" dan "u" sebagai contoh: come /kım/, call $/ \mathrm{k} \mathrm{l} /$, cut $/ \mathrm{k} \Lambda \mathrm{t} /$. Sedangkan perubahan suara di huruf "c" menjadi suara /s/ terjadi apabila huruf "c" bertemu dengan huruf "i", "y" dan "e" sebagai contoh city /sit.i/, cycle /sar.k1/, certificate /sətıf.r.kət/. Dengan mengetahui peraturan tersebut siswa akan mempunyai kemampuan memahami kata, seperti pernyataan yang disampaikan oleh Vaisman \& Kahn-Horwitz (2020) bahwa mempunyai kemampuan memahami kata sangat penting bagi siswa yang belajar bahasa Inggris. Kemampuan dalam memahami kata ini dapat dilakukan dengan membiasakan untuk membaca. Kebiasaan membaca akan dapat mampu mengembangkan pemahaman dan keberhasilan dalam pembelajaran (Haryadi, 2020). Lebih-lebih bahasa Inggris dianggap sebagai bahasa asing yang sulit untuk ditulis dan dipelajari, maka dari pada itu sangat penting untuk menerapkan phonics secara sistematis dan bertahap di dalam kelas (Buckingham, 2019) agar dapat meningkatkan keakuratan dalam membaca juga meningkatkan pemahaman terhadap kata (Taylor et al., 2017). Oleh sebab itu tujuan diterapkan pembelajaran phonics melalui RABS pada siswa SMP Qurrotul Uyun agar siswa mampu melafalkan kata bahasa Inggris dengan tepat dan benar, meminimalkan tingkat kesalahan saat mengucapkan, saat membaca 
ataupun menulis kata bahasa Inggris, dan menjadikan mereka sebagai reader (pembaca) ataupun writer (penulis) kata atau kalimat bahasa Inggris yang lebih baik.

\section{METODE}

Bentuk kegiatan yang dilakukan dalam pengabdian masyarakat ini adalah pelatihan dan pendampingan dengan melibatkan 17 siswa kelas 7 SMP Qurrotul Uyun Pamekasan-Madura sebagai sasaran utamanya. Adapun siswa kelas 7 terdiri dari perempuan berjumlah 10 siswa dan laki-laki berjumlah 7 siswa. Tujuan siswa kelas 7 dilibatkan dalam kegiatan ini agar kemampuan bahasa Inggris mereka menjadi lebih baik dan bertambah meningkat terutama dalam melafalkan kata atau kalimat bahasa Inggris. Serta untuk meminimalkan tingkat kesalahan dalam melafalkan kata terutama saat menggunakan bahasa Inggris ketika berbicara, menulis ataupun membaca. Sehingga harapannya nanti ketika mereka berada di kelas berikutnya yaitu kelas 8 dan 9 mereka bisa menggunakan bahasa Inggris dengan baik, terhindar dari kesalahan pelafalan, terampil melafalkan kata atau kalimat bahasa Inggris dengan jelas dan benar, serta dapat digunakan sebagai bekal bagi mereka nanti ketika ingin mendapatkan pekerjaan yang lebih baik atau untuk melanjutkan ke perguruan tinggi favorit ketika mereka sudah lulus dari sekolah menengah atas.

Dalam melaksanakan kegiatan pelatihan dan pendampingan ini tim abdimas menjalankan tahapan-tahapan sebagai berikut: 1) Mempresentasikan materi pelatihan melalui power point. Materi pelatihan yang disampaikan meliputi pengetahuan tentang phonics melalui RABS (Rhyming, Alliteration, Blending dan Segmentation) dalam pembelajaran pelafalan kata bahasa Inggris. 2) Memberikan penjelasan tentang tahapan-tahapan RABS beserta contohnya. 3) Memberikan pelatihan mengenai bagaimana melafalkan kata bahasa Inggris dengan tepat dan benar melalui phonics dengan tahapan-tahapan RABS nya. 4) Melakukan pendampingan untuk mengetahui bagaimana respon para siswa saat menerapkan phonics melalui RABS. Pendampingan ini bertujuan untuk memantapkan bahwa para siswa mempunyai kemampuan untuk melafalkan kata bahasa Inggris dengan baik dan benar. Dan kegiatan pendampingan ini dilakukan secara langsung yaitu melalui tatap muka dengan siswa ataupun secara tidak langsung yaitu melalui email. 5) Melakukan evaluasi dengan menyebarkan lembar angket pretest \& dan post- test pada semua siswa.

\section{HASIL DAN PEMBAHASAN}

Pelaksanaan kegiatan pengabdian ini dilaksanakan selama tiga hari yaitu pada hari Senin tanggal 25, hari Selasa tanggal 26 dan hari Rabu tanggal 27 di bulan Januari 2021. Pada hari pertama, hari Senin jam 08.00 WIB tanggal 25 Januari 2021, pelaksanaan kegiatan pelatihan diawali dengan penyampaian sambutan dari ketua pelaksana program yang menyampaikan informasi tentang agenda dan tujuan kegiatan pengabdian masyarakat. Kemudian diteruskan dengan melakukan pretest pada siswa dengan cara mendistribusikan kusioner pada seluruh siswa yang terdiri 
dari 4 pertanyaan yang dapat dilihat di tabel 1 tentang pengetahuan phonics dalam pembelajaran pelafalan kata bahasa Inggris.

Tabel. 1 Hasil pre-test dan post-test tentang pengetahuan phonics

\begin{tabular}{|l|l|c|c|c|c|}
\hline \multirow{2}{*}{ No } & \multicolumn{1}{|c|}{ Pertanyaan } & \multicolumn{2}{c|}{ Pre-test } & \multicolumn{2}{c|}{ Post-test } \\
\cline { 3 - 5 } & & ya & tidak & ya & tidak \\
\hline 1 & $\begin{array}{l}\text { Pernahkah kalian mendengar tentang phonics } \\
\text { dalam pembelajaran pelafalan kata bahasa } \\
\text { Inggris? }\end{array}$ & $0 \%$ & $100 \%$ & $100 \%$ & $0 \%$ \\
\hline 2 & $\begin{array}{l}\text { Apakah kalian mengetahui bagaimana } \\
\text { menerapkan phonics yang terdiri dari tahapan } \\
\text { RABS (Rhyming, Alliteration, Blending dan } \\
\text { Segmentation)? }\end{array}$ & $0 \%$ & $100 \%$ & $100 \%$ & $0 \%$ \\
\hline 3 & $\begin{array}{l}\text { Apakah kalian mengetahui tujuan dari } \\
\text { penerapan phonics dalam pembelajaran } \\
\text { pelafalan kata bahasa Inggris ? }\end{array}$ & $0 \%$ & $100 \%$ & $100 \%$ & $0 \%$ \\
\hline 4 & $\begin{array}{l}\text { Apakah kalian mempunyai keinginan untuk } \\
\text { menerapkan phonics melalui RABS saat belajar } \\
\text { melafalkan kata bahasa Inggris di kelas? }\end{array}$ & $0 \%$ & $100 \%$ & $100 \%$ & $0 \%$ \\
\hline
\end{tabular}

Hasil kuesioner pada tabel 1 menunjukkan bahwasannya siswa yang pernah mendengar istilah phonics adalah 0\%. Dan 100\% siswa tidak tahu sama sekali bagaimana menerapkan phonics dengan menggunakan tahapan RABS. Ini menunjukkan bahwa siswa tidak pernah belajar bahasa Inggris, terlebih belajar pelafalan kata, dengan menerapkan phonics. Berdasarkan pada temuan tadi maka dapat disimpulkan bahwa kegiatan pelatihan ini sangat diperlukan untuk memberikan pengetahuan pada para siswa tentang penerapan phonics melalui RABS sehingga siswa nantinya menjadi terampil melafalkan kata bahasa Inggris.

Setelah mendistribusikan kuesioner tim abdimas melakukan presentasi pemaparan materi mengenai penerapan phonics melalui RABS, menjelaskan satu persatu tahapan RABS, memberikan contoh satu persatu tahapan RABS, melakukan kegiatan atau praktik yang terdapat pada tahapan RABS, serta melakukan diskusi atau tanya jawab. Kegiatan pengabdian pada hari pertama ini, selama kurang lebih 60 menit tim abdimas menjelaskan, memberikan contoh sekaligus melakukan pelatihan atau praktik yang terdapat pada tahapan Rhyming dan Alliteration kepada para siswa.

\section{RHYMING}

Rhyming adalah kata-kata yang suku kata akhirnya mempunyai suara atau bunyi yang sama. Seperti kata: let, get, met, pet, wet. Suara yang sama (rhyme) pada kata-kata tersebut terletak pada suara yang ada di akhir kata, yaitu suara /et/. Pada tahapan pertama ini, tim abdimas terlebih dahulu menggunakan power point untuk memberikan penjelasan mengenai definisi dan manfaat phonics dalam pembelajaran bahasa Inggris. Tim abdimas memperlihatkan slide pada siswa kelas tujuh yang berisi beberapa contoh kata-kata yang ber-rhyming, yaitu kata yang memiliki suara yang sama di akhir kata, dan kata-kata yang tidak ber-rhyming, yaitu kata yang memiliki suara yang tidak sama di akhir kata seperti yang dapat dilihat pada gambar 1; 

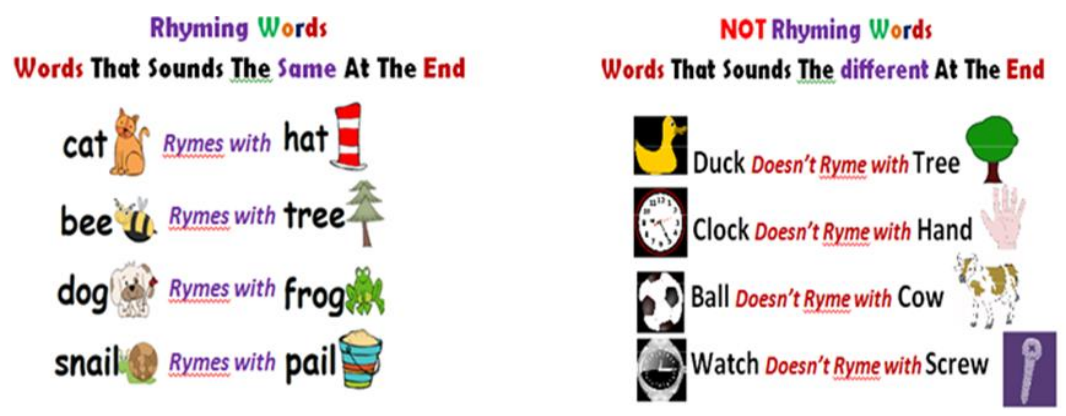

Gambar 1. Contoh kata yang ber-rhyming dan yang tidak ber-rhyming

Setelah memperlihatkan contoh kata-kata yang ber-rhyming dan kata-kata yang tidak ber-rhyming, tim abdimas meminta siswa kelas 7 untuk mendengarkan dengan seksama kata-kata yang sedang dilafalkan oleh tim abdimas. Adapun katakata tersebut adalah kata-kata yang ber-rhyming dan kata-kata yang tidak berrhyming yang terdapat pada contoh di gambar 1 . Kemudian tim abdimas meminta siswa untuk mengidentifikasi kata-kata mana saja yang ber-rhyming dan kata-kata mana saja yang tidak ber-rhyming. Setelah itu siswa diminta untuk melafalakan kata yang ber-rhyming dan yang tidak dengan jelas, benar dan diulang-ulang. Kegiatan pengulangan pelafalan kata dilakukan agar siswa lebih fokus dan memperhatikan setiap bunyi yang ada pada kata per kata dan setiap bunyi yang ada di akhir kata. Sehingga dengan melakukan kegiatan tersebut, kemampuan melafalkan (pronunciation skill) dan kemampuan membaca (reading skill) siswa diharapkan menjadi lebih baik. Hasil dari kegiatan ini dapat dilihat pada tabel 2 yang menunjukkan bahwa semua contoh kata bahasa Inggris baik yang ber-rhyming ataupun yang tidak ber-rhyming dilafalkan dengan tidak benar. Setelah tim abdimas memberikan contoh-contoh pelafalan kata bahasa Inggris yang benar (seperti yang ada pada tabel 2) dan meminta para siswa untuk melakukan pengulanganpengulangan pelafalan kata dengan memperhatikan contoh-contoh pelafalan kata yang benar, kata-kata bahasa Inggris yang dilafalkan para siswa menjadi lebih baik daripada sebelumnya. Pelafalan-pelafalan kata bahasa Inggris mereka benar semua karena sesuai dengan contoh-contoh pelafalan kata yang diberikan oleh tim abdimas.

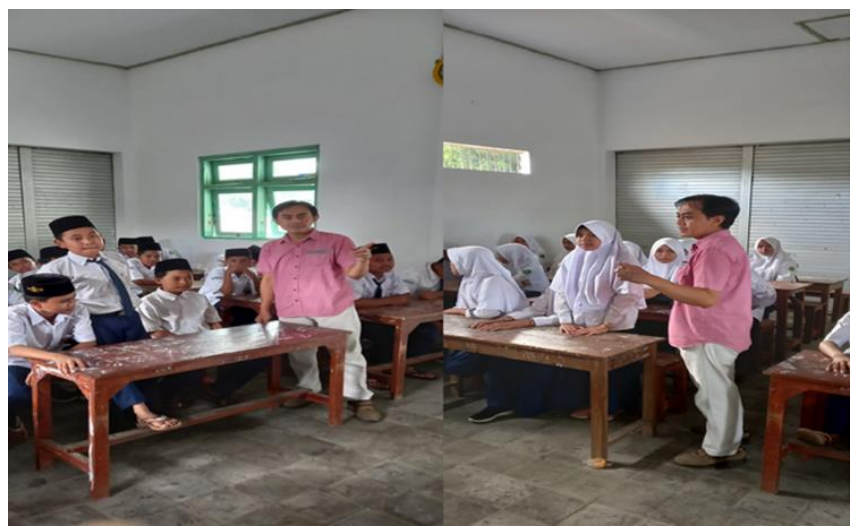

Gambar 2. Ketika Siswa Melakukan Kegiatan Rhyming 
Tabel. 2 Hasil latihan melafalkan kata yang ber- rhyming dan yang tidak

\begin{tabular}{|c|c|c|c|c|c|c|c|c|}
\hline \multirow{3}{*}{ Siswa } & \multicolumn{8}{|c|}{ Rhyming } \\
\hline & \multicolumn{4}{|c|}{ Contoh kata yang ber-rhyming } & \multicolumn{4}{|c|}{ Contoh kata yang tidak ber-rhyming } \\
\hline & Hat & Three & Snail & Bee & Watch & Duck & Clock & Screw \\
\hline 1 & /hat / & /tre / & /snel/ & /ba / & /wat / & $\mid d u k /$ & / clok/ & / secrew / \\
\hline 2 & $/ h \wedge t /$ & /tre / & /snail / & $/ b a /$ & /wot / & $/ d u k /$ & /clok/ & / secrew / \\
\hline 3 & /hat / & /tri/ & /snel/ & /ba/ & /wot / & $/ d u k /$ & / clok/ & / secrew / \\
\hline 4 & $/ h \wedge t /$ & /tre / & /snel/ & /ba / & /wat / & $/ d u c /$ & / clok/ & / secrew / \\
\hline 5 & $/ h \wedge t /$ & /tri/ & /snel/ & /ba / & /wat / & $/ d u c /$ & / clok/ & / secrew / \\
\hline 6 & /hıt/ & /tri/ & / snel/ & /ba / & / wat / & $/ d u c /$ & / clok / & / secrew / \\
\hline 7 & /hıt / & /tri / & /snel/ & /ba / & / wat / & $/ d u c /$ & / clok / & / secrew / \\
\hline 8 & / hat / & /tri / & / snel/ & /ba / & /wat / & $/ d u c /$ & / clok / & / secrew / \\
\hline 9 & / hat / & /tre / & /snel/ & /ba / & /wat / & $/ d u c /$ & / clok / & / secrew / \\
\hline 10 & / hat / & / tre / & / snel / & /ba / & / wat / & $\mid d u k /$ & / clok / & / secrew / \\
\hline 11 & / hat / & /tre / & /snail / & /be / & / wot / & $/ d u k /$ & / clok / & / secrew / \\
\hline 12 & / hat / & / tre / & / snail / & /be / & / wot / & $/ d u k /$ & / clok / & / secrew / \\
\hline 13 & / hat / & / tre / & / snail / & /be / & / wot / & /duk/ & / clok / & / secrew / \\
\hline 14 & / hat / & /tre / & / snail / & /be / & / wot / & $/ d u k /$ & / clok / & / secrew / \\
\hline 15 & $/ h \wedge t /$ & / tre / & / snail / & /be / & / wot / & $/ d u k /$ & / clok / & / secrew / \\
\hline 16 & / hat / & /tri / & / snail / & /be / & / wot / & $/ d u k /$ & / clok / & / secrew / \\
\hline 17 & / hat / & /tre / & / snail / & /be / & / wot / & $\mid d u k /$ & / clok / & / secrew / \\
\hline \multicolumn{9}{|c|}{ Pelafalan kata yang benar } \\
\hline & Hat & Three & Snail & Bee & Watch & Duck & Clock & Screw \\
\hline & / hoet / & / Ori: / & / sneil / & / bi: / & / wpt $\int /$ & $/ \mathrm{d} \Lambda \mathrm{k} /$ & / klpk / & / skru: / \\
\hline
\end{tabular}

Untuk mengembangkan kemampuan siswa dalam rhyming, tim abdimas juga memberikan pelatihan yang berbeda dengan cara melakukan deleting : menghapus, adding : menambhakan dan substituting : menggantikan suara-suara yang ada pada suatu kata seperti : kata "Cat" yang berbunyi /kæt/, suara atau bunyi /k/ yang ada di depan kata tersebut di ganti (substituting) dengan suara /b/ sehingga kata tersebut menjadi kata "Bat" yang berbunyi /bæt/. Pada kegiatan pelatihan ini, terdapat pendampingan yang dilakukan dengan cara tatap muka pada para siswa untuk memberikan penilaian terhadap kemampuan mereka dalam melakukan kegiatan rhyming. Selain itu, tim abdimas juga memberikan pendampingan lebih lanjut pada siswa melalui media komunikasi e-mail yang mana sebelumnya siswa diwajibkan membuat e-mail. Hal ini dilakukan agar siswa bisa mengerjakan latihan-latihan yang diberikan oleh tim abdimas melalui e-mail untuk mengembangkan kemampuan mereka dalam rhyming dan juga bisa membuat contoh sendiri selain contoh yang diberikan oleh tim abdimas. Sehingga para siswa benar-benar mampu melakukan kegiatan rhyming dengan baik dan benar.

\section{ALLITERATION}

Alliteration dapat didefinisikan sebagai pengulangan suara konsonan yang sama yang terdapat di beberapa kata dan suara konsonan yang diulang tersebut terletak di awal kata. Ini juga bisa diartikan bahwa bukan huruf konsonan yang terletak di awal kata yang terjadi pengulangan, akan tetapi suara konsonannya yang mengalami pengulangan. Seperti di frase "Kid's candy" yang alliterative (huruf 
konsonan yang terdapat di awal kata-kata tersebut menglami pengulanagan suara yang sama) karena meskipun huruf awal konsonan pada dua kata tersebut berbeda, yaitu huruf " $\mathrm{K}$ " dan huruf "c" namun keduanya menghasilkan suara yang sama, yaitu suara /k/, sehingga dapat dibaca seperti ini: /kıdz kæn.di/. Sedangkan contoh kata-kata yang tidak alliterative seperti "Phone person". Meskipun ke dua kata tersebut diawali dengan huruf konsonan yang sama, yaitu huruf "p" namun suara awal konsonan mereka berbeda saat dilafalkan, seperti "ph" di phone menghasilkan suara /f/ ketika di lafalkan. Sehingga kata phone bersuara /fəon/. Dan kata person suara awal konsonannya tetap berbunyi /p/.
a. Kate knows that coca cola contains a sweet dark-brown drink
b. Some snakes slide silently sideways
c. Tall Tom takes two tomatoes
d. Fran's friends fried Fritos for Friday's food

Siwa diminta membaca kalimat tersebut 2 sampai 3 kali dengan suara yang nyaring. Selesai mengulang membaca kalimat tadi beberapa kali, siswa diberikan pertanyaan mengenai frase atau kata-kata mana saja yang alliterative dan yang tidak. Setelah itu beberapa siswa diminta untuk menuliskan kata mana saja yang huruf depannya mempunyai huruf konsonan yang sama (seperti huruf konsosnan "K" yang terdapat pada kata Kate, knows, huruf konsonan "C" yang terdapat pada kata coca, cola, contains, dan huruf konsonan "D" yang terdapat pada kata dark, drink) dan kata mana saja yang huruf depannya mempunyai atau menghasilkan suara yang sama (seperti suara /k/ yang terdapat pada kata Kate/kaet/, coca /koka/, cola /kola/ dan contain /kontein/, suara /d/ yang terdapat pada kata dark/dak/ dan kata drink/drink/. Saat pelatihan, hanya 4 siswa yang hasil latihannya tidak bagus seperti yang dapat dilihat pada tabel 3. Sedangkan 13 siswa dapat mengerjakan latihan alliteration dengan baik dan tidak membuat kesalahan. Ini menunjukkan bahwa banyak siswa kelas 7 yang memiliki kemampuan yang baik saat mempraktekkan melafalkan kata bahasa Inggris melalui cara alliteration.

Tabel 3. Hasil Latihan huruf konsonan

\begin{tabular}{|c|c|c|c|}
\hline \multirow{2}{*}{ Siswa } & \multicolumn{3}{|c|}{ Jenis latihan } \\
\hline & Alliteration & Blending & Segmentation \\
\hline 1 & $\sqrt{ }$ & $\sqrt{ }$ & $\sqrt{ }$ \\
\hline 2 & $\sqrt{ }$ & $\sqrt{ }$ & $\sqrt{ }$ \\
\hline 3 & $\sqrt{ }$ & $\sqrt{ }$ & $\sqrt{ }$ \\
\hline 4 & $\sqrt{ }$ & $\sqrt{ }$ & $\sqrt{ }$ \\
\hline 5 & $\mathrm{X}$ & $\sqrt{ }$ & $\mathrm{X}$ \\
\hline 6 & $\sqrt{ }$ & $\sqrt{ }$ & $\sqrt{ }$ \\
\hline 7 & $\sqrt{ }$ & $\mathrm{X}$ & $\sqrt{ }$ \\
\hline 8 & $\sqrt{ }$ & $X$ & $\sqrt{ }$ \\
\hline 9 & $\sqrt{ }$ & $\sqrt{ }$ & $\sqrt{ }$ \\
\hline 10 & $\mathrm{X}$ & $\mathrm{X}$ & $\mathrm{X}$ \\
\hline 11 & $X$ & $X$ & $X$ \\
\hline 12 & $\mathrm{X}$ & $\mathrm{X}$ & $\sqrt{ }$ \\
\hline 13 & $\sqrt{ }$ & $\sqrt{ }$ & $\sqrt{ }$ \\
\hline 14 & $\sqrt{ }$ & $\sqrt{ }$ & $\sqrt{ }$ \\
\hline
\end{tabular}




\begin{tabular}{|c|c|c|c|}
\hline 15 & $\sqrt{ }$ & $\sqrt{ }$ & $\sqrt{ }$ \\
\hline 16 & $\sqrt{ }$ & $\sqrt{ }$ & $\sqrt{ }$ \\
\hline 17 & $\sqrt{ }$ & $X$ & $\sqrt{ }$ \\
\hline \multirow{2}{*}{ Keterangan } & \multicolumn{3}{|c|}{$\begin{array}{l}\sqrt{ } \text { : Siswa mampu mengerjakan latihan dengan baik dan tidak } \\
\text { membuat kesalahan }\end{array}$} \\
\hline & \multicolumn{3}{|c|}{$\begin{array}{l}\text { X : Siswa tidak mampu mengerjakan latihan dengan baik dan } \\
\text { membuat kesalahan }\end{array}$} \\
\hline
\end{tabular}

Pada hari kedua, hari selasa jam 08.00 WIB tanggal 26 Januari 2021, peserta kembali hadir untuk mengikuti pelatihan penerapan phonics melalui RABS. Kegiatan pengabdian pada hari kedua ini, selama kurang lebih 60 menit tim abdimas menjelaskan, memberikan contoh sekaligus melakukan pelatihan atau praktik yang terdapat pada tahapan blending dan segmentation kepada para siswa.

\section{BLENDING}

Blending adalah suatu kemampuan untuk bisa mengidentifikasi suara-suara kata yang diucapkan sehingga kata-kata yang sudah teridentifikasi menjadi katakata yang mudah dikenal (familiar) karena siswa biasanya cenderung tidak bisa melafalkan kata-kata yang tidak familiar. Agar siswa bisa membaca atau melafalkan kata-kata yang tidak familiar, siswa harus terlebih dahulu mengetahui tiap-tiap suara yang terdapat pada suatu kata, bukan mengetahui tiap-tiap huruf yang terdapat pada suatu kata. Seperti pada kata "thin" siswa harus mengetahui atau membunyikan suara $/ \boldsymbol{t h} /$ - /i/ dan suara /n/ bukan mengetahui huruh 't' -'h' ' 'i' dan huruf 'n'. Setelah siswa mengetahui tiap-tiap suara / fonem /th- i-n/ siswa kemudian menggabungkannya bersama-sama (blending) untuk membentuk kata thin.

Pada tahapan ketiga ini, tim abdimas membuat contoh dengan menuliskan satu atau beberapa kata di papan tulis. Tim abdimas memberikan penjelasan dan contoh bagaimana mem-blending kata seperti yang terdapat pada kata "make". Kemudian tim abdimas menunjuk beberapa siswa untuk menyuarakan tiap-tiap suara yang terdapat pada kata yang telah dijadikan sebagai contoh tadi. Maksud dari menyuarakan tiap-tiap suara pada suatu kata adalah menginstruksikan siswa untuk membunyikan suara pertama $/ \boldsymbol{m} /$, suara kedua /ei/ dan suara terakhir / $/$ / yang terdapat pada kata "make" kemudian menggabungkan tiap-tiap suara tadi secara bersamaan untuk dijadikan kata "make", dan menyuruh siswa untuk membacanya dengan nyaring. Hasil pelatihan dari pada tabel 3 menunjukkan bahwa terdapat 6 siswa yang tidak bisa melakukan blending dengan baik. Mereka melakukan kesalahan saat latihan. Sedangkan 11 siswa dapat mengerjakan latihan alliteration dengan baik dan tidak membuat kesalahan. Ini menandakan banyak siswa kelas 7 yang memiliki kemampuan yang baik saat mempraktekkan melafalkan kata bahasa Inggris melalui cara blending.

\section{SEGMENTATION}

Segmentation merupakan sebuah strategi untuk membantu mengembangkan kemampuan phonologi siswa. Segmentation juga dapat diartikan sebagai suatu kemampuan untuk mengidentifikasi setiap suara yang terdapat pada kata yang 
diucapkan dengan cara membelahnya atau memisahkannya, seperti kata home yang dapat dibelah menjadi suara : /h/ $-/ \boldsymbol{o} /-/ \boldsymbol{m} /-/ \boldsymbol{e} /$. Dengan kata lain Segmentation adalah suatu kemampuan untuk memisahkan atau membelah suatu suara yang terdapat pada suatu kata

Pada tahapan keempat ini, ada tiga langkah yang dilakukan tim abdimas dalam mempratekkan segmenting pada siswa, yaitu :

a) Segmenting first sound, yaitu menginstruksikan siswa untuk memisahkan suara pertama saja,

contoh:

Tim abdimas : "Apa suara pertama yang ada pada kata bag ?"

Siswa : “/b/"

Tim abdimas : : "Apa suara pertama yang ada pada kata hat ?"

Siswa : "“/h/"

b) Segmenting onset-rime, yaitu pertama-tama siswa diminta untuk mendengarkan semua bunyi kata yang diucapakan oleh tim abdimas, kemudian siswa diminta untuk melafalkan atau membunyikan huruf pertama yang ada pada kata tersebut dan setelah itu melafalkan semua sisa huruf yang ada kata tersebut. Contoh :

Tim abdimas : "Coba lafalkan suara yang ada pada kata rice !"

Siswa : “/r/ - /ice/"

Tim abdimas : "Home"

Siswa : "“/h/ - /ome/"

c) Segmenting individual sounds, yaitu siswa diinstruksikan mendengarkan suatu kata yang diucapakan oleh tim abdimas, setelah itu siswa diminta untuk menyuarakan setiap bunyi yang ada pada kata tersebut. Contoh :

Tim abdimas : "Coba lafalkan suara-suara yang ada pada kata school!"

Siswa $\quad:$ “/s/ - / $/ \mathbf{k} /-/ \mathbf{o u} /-/ \mathbf{o u} /-\mathbf{~} /$ "

Tim abdimas : "Meat"

Siswa $\quad: “ / \mathbf{m} /-/ \mathbf{i} /-/ \mathbf{e} /-/ \mathbf{t} / "$

Pada hari ketiga, hari rabu jam 08.00 WIB tanggal 27 Januari 2021, merupakan hari terakhir dari kegiatan pengabdian dan pelatihan ini. Para peserta diberikan kuesioner (post-test) yang isi dan jumlah pertanyaannya sama dengan kuesioner di tabel 1. Dari hasil kuesioner yang ada di tabel 1 dapat ditarik kesimpulan bahwa semua siswa (100\%) berkeinginan untuk menerapkan phonics melalui RABS saat belajar melafalkan kata bahasa Inggris di kelas. Mereka menyadari bahwasannya ketika mempraktikkan RABS di kegiatan pelatihan ini mereka mendapatkan banyak pengetahuan seperti pengetahuan fonologi, pengetahuan membaca dan pengetahuan mengeja. Mereka juga menyadari bahwa belajar melafalkan kata bahasa Inggris melalui phonics itu dapat membantu meningkatkan kemampuan membaca, mendengar, menulis mereka menjadi lebih baik. Di samping itu, untuk memperbaiki hasil latihan rhyming, alliteration, blending dan segmentation yang tidak baik yang dilakukan oleh beberapa siswa, tim abdimas memberikan lagi pelatihan, pendampingan dan evaluasi pada mereka 
melalui e-mail dengan harapan nanti kemampuan mereka belajar bahasa Inggris melalui RABS akan menjadi lebih baik dari pada sebelumnya.

\section{KESIMPULAN}

Pembelajaran phonics yang diterapkan melalui tahapan rhyming, alliteration, blending dan segmentation pada siswa kelas 7 SMP Qurrotul Uyun Pamekasan yang sehari-harinya menggunakan bahasa Madura sebagai bahasa Ibu mereka tidak hanya dapat membantu menambah pengetahuan English phonology mereka tetapi juga dapat membantu meningkatkan ketrampilam mereka dalam melafalkan huruhhuruf bahasa Inggris dan kata-kata bahasa Inggris. Karena ketika metode phonics ini sedang diterapkan di kelas, secara tidak langsung siswa dapat belajar bagaimana membunyikan setiap huruf yang ada pada suatu kata bahasa Inggris dengan benar, dapat belajar pembentukan huruf, dan dapat belajar bagaimana menggabungkan, mengidentifikasi suara atau bunyi yang terdapat pada suatu kata bahasa Inggris. Sehingga pembelajaran phonics yang diterapkan untuk siswa kelas 7 SMP Qurrotul Uyun Pamekasan dapat membantu memudahkan mereka belajar bahasa Inggris dalam melafalkan kata atau kalimat bahasa Inggris dengan benar dan tepat. Mengingat melafalkan kata bahasa Inggris dengan benar tidaklah mudah bagi siswa yang bukan penutur bahasa aslinya, maka sebaiknya siswa diberikan strategi pembelajaran yang dapat membuat siswa tertarik, termotivasi untuk belajar dan mempraktekkan melafalkan kata bahasa Inggris dan salah satu contoh strategi pembelajaran yang dapat diterapkan adalah pembelajaran phonics melalui RABS

\section{DAFTAR PUSTAKA}

Albiladi, W. S. (2019). Teaching English pronunciation revisited: the challenges of teaching EFL in non-English-speaking countries. European Journal of Foreign Language Teaching, 4(3), 41-50. https://doi.org/10.5281/zenodo.3566658

Buckingham, J. (2019). Focus on Phonics: Why Australia should adopt the Year 1 Phonics Screening Check. The Centre for Independent Studies. Retrieved from https://www. cis. org. au ....

Gilakjani, A. P. (2016). What factors influence the English pronunciation of EFL learners? Modern Journal of Language Teaching Methods, 6(2), 315.

Grado, T. F. I. N. D. E. (2014). Grado en Educación Infantil (Mención Inglés) An introduction to Phonics: Pronunciation strategies in the Primary English Classroom Presentado por Elena Escolán Tutelado por: Francisco José Francisco Carrera.

Griffiths, B. (2011). Integrating pronunciation into classroom activities. British Council \& BBC.

Haryadi, R. N. (2020). Pengaruh Pengaruh Kebiasaan Membaca Terhadap Kemampuan Berbicara Bahasa Inggris SMA Negeri 99 Jakarta. Jurnal Manajemen Bisnis Dan Keuangan, 1(2), 14-30.

Harmer, J. (2001). The practice of English language teaching. London/New York, 401-405. 
Hismanoglu, M., \& Hismanoglu, S. (2011). Internet-based pronunciation teaching: An innovative route toward rehabilitating Turkish EFL learners' articulation problems. European Journal of Educational Studies, 3(1), 23-36.

James, R. B. (2010). Teaching pronunciation gets a bad RAP: A framework for teaching pronunciation. Hankuk: University of Foreign Studies.

Shahzada, G., Khan, U. A., \& Mehmud, A. (2012). Views of the teachers regarding the students' poor pronunciation in English language. Journal of Educational and Social Research, 2(1), 309.

Taylor, J. S. H., Davis, M. H., \& Rastle, K. (2017). Comparing and validating methods of reading instruction using behavioural and neural findings in an artificial orthography. Journal of Experimental Psychology: General, 146(6), 826.

Yuangga, K. D., \& Sunarsi, D. (2020). Pengembangan media dan strategi pembelajaran untuk mengatasi permasalahan pembelajaran jarak jauh di pandemi covid-19. JGK (Jurnal Guru Kita), 4(3), 51-58.

Vaisman, E. E., \& Kahn-Horwitz, J. (2020). English foreign language teachers' linguistic knowledge, beliefs, and reported practices regarding reading and spelling instruction. Dyslexia, 26(3), 305-322. 